\title{
Use of Skin Substitute Dressings in the Treatment of Staphylococcal Scalded Skin Syndrome in Neonates and Young Infants
}

\author{
M.G.A. Baartmans ${ }^{a} \quad$ J. Dokter ${ }^{b} \quad$ J.C. den Hollander ${ }^{c}$ A.A. Kroon ${ }^{d}$ A.P. Oranje ${ }^{e}$ \\ ${ }^{\mathrm{a}}$ Department of Paediatrics and ${ }^{\mathrm{b}}$ Burn Centre, Maasstadziekenhuis, ' $\mathrm{C}$ epartment of Pathology, Erasmus MC, \\ ${ }^{\mathrm{d}}$ Department of Paediatrics, Sub-Department of Neonatology, and ${ }^{\mathrm{e}}$ Department of Paediatric Dermatology, \\ Erasmus MC-Sophia Children's Hospital, Rotterdam, The Netherlands
}

\section{Established Facts}

- No adhesive wound dressings for neonates with SSSS.

\section{Novel Insights}

- Skin therapy with adhesive skin substitutes in neonates.

- Practical guidelines for treatment of neonates with servere SSSS.

\section{Key Words}

Infants, neonates - Staphylococcal infections •

Staphylococcal scalded skin syndrome - Skin substitutes • Guidelines

\begin{abstract}
Background: Staphylococcal scalded skin syndrome (SSSS) is a rare toxin-mediated skin disease caused by Staphylococcus aureus and seen in infants and children younger than 5 years. Objectives: The supportive role of skin substitutes in SSSS is stressed as a new and relatively unknown method. Methods: Retrospective observational case-series study, in neonates and young infants diagnosed with SSSS. Results: Seven infants with SSSS, treatment with antibiotics, skin sub-
\end{abstract}

stitutes, strict pain relief strategy and prognosis were described. One of them was severely affected and deceased. Conclusion: This study describes 7 infants with SSSS and stresses the important role of skin substitutes as Omiderm ${ }^{\circledR}$ and Suprathe ${ }^{\circledR}$ as valuable adjuvant treatment modality.

Copyright $\odot 2010$ S. Karger AG, Basel

\section{Introduction}

Staphylococcal scalded skin syndrome (SSSS) is a toxin-mediated skin disease caused by Staphylococcus aureus and usually seen in neonates and children younger than 5 years. It is rarely seen in adults. $S$. aureus produces exfoliative toxins which destroy the desmosomes in the

\section{KARGER}

Fax +41613061234 E-Mail karger@karger.ch www.karger.com
(C) 2010 S. Karger AG, Basel

$1661-7800 / 11 / 1001-0009 \$ 38.00 / 0$

Accessible online at:

www.karger.com/neo
M.G.A. Baartmans, MD

Department of Paediatrics/Burn Centre, Maasstadziekenhuis

PO Box 9100, NL-3007 AC Rotterdam (The Netherlands)

Tel. +31 102913 184, Fax +31 102913407

E-Mail Baartmansm@maasstadziekenhuis.nl 

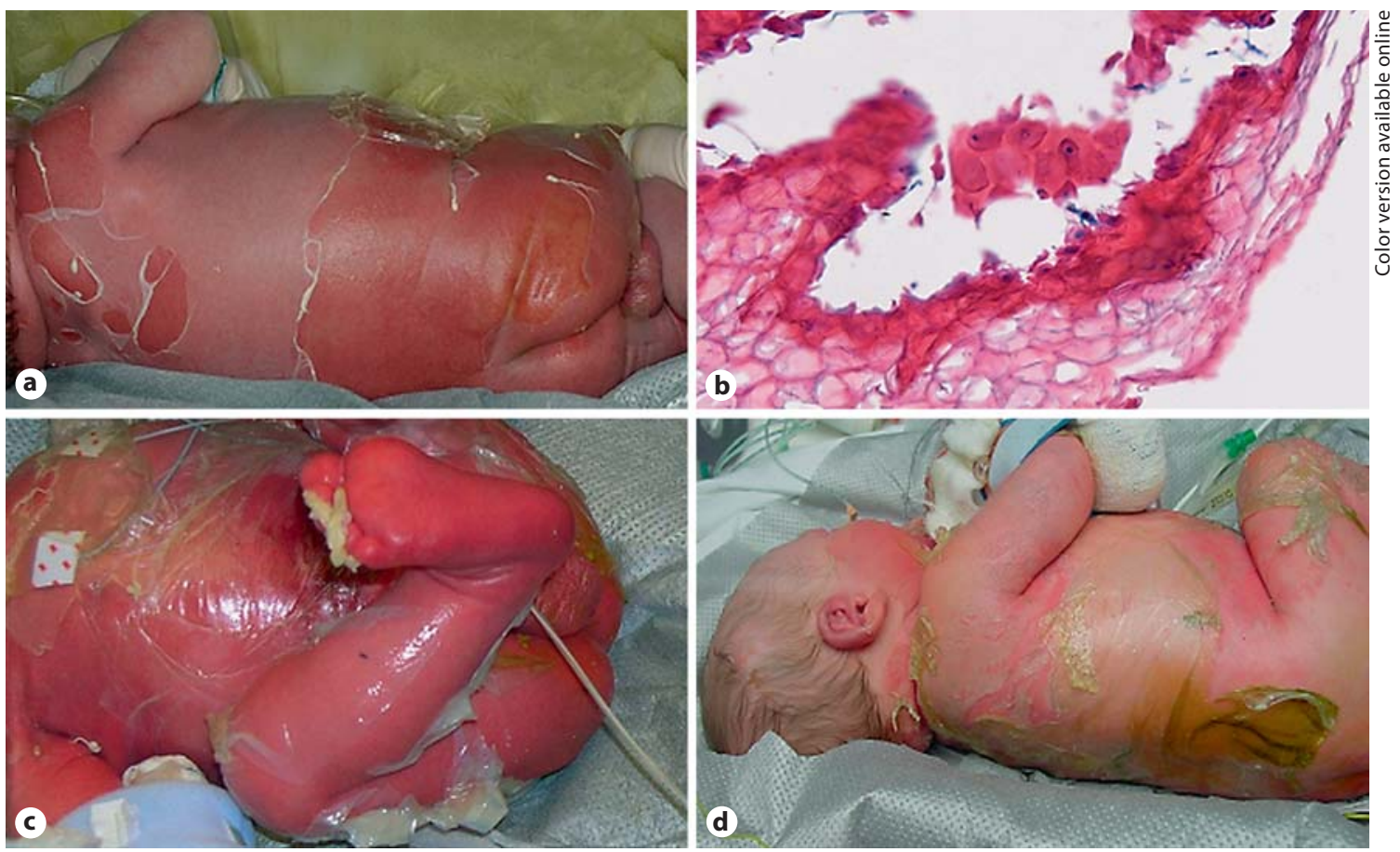

Fig. 1. a Scald appearance with blisters and erythema of the trunk. b Acantholytic cells in the subcorneal region. c Abdomen and legs covered with Omiderm ${ }^{\circledR}$. d Omiderm ${ }^{\circledR}$ treatment after 4 days.

stratum granulosum of the skin. Clinically, there are superficial blisters without mucosal lesions $[1,2]$.

SSSS usually presents with sore throat and purulent conjunctivitis as the source of infection. In neonates, the umbilical cord is often the source of infection. Within $48 \mathrm{~h}$ the patient develops fever, malaise and extremely tender erythematous areas on the face, neck, axilla and perineum (fig. 1a). Flaccid bullae develop within the erythematous areas and the Nikolsky's sign is positive [2]. The bullae generally affect the bending sides of the extremities and large areas of the skin may be affected. Bullae enlarge and rupture easily to reveal a moist erythematous base, which gives rise to the scalded appearance. The diagnosis of SSSS is clinically and by histopathological examination of a sample from the roof of a blister (fig. 1b).

Healing occurs without scarring. SSSS usually resolves within 7 days but management may be very challenging and complicated including repeated and daily use of sedatives and analgesics for skin treatment [4-7]. Adhesive wound dressings are not recommended for SSSS, but are practical solutions for skin substitution in burns $[8,9]$. In this communication, we introduce the treatment of 7 infants with SSSS treated with adhesive skin substitutes such as Omiderm ${ }^{\circledR}$ or Suprathel ${ }^{\circledR}$.

\section{Method}

We collected retrospective data of children younger than 1 year of age admitted to the hospital with SSSS over a period of 4 years (2004-2008). Data were collected in two medical centers, Erasmus MC-Sophia Children's Hospital and Burn Centre Maasstadziekenhuis, Rotterdam, The Netherlands. Age, gender, total affected area, culture results, histopathology, time of intensive care treatment, amount of analgesics and sedatives, skin treatment, and length of stay were evaluated.

\section{Results}

In table la patient data are summarized. Patient 5 has been published before [10]. Four neonates and 3 infants were analyzed. All patients were infected with $S$. aureus and needed intensive care support. All patients required opioid infusion (morphine) and all received paracetamol (acetaminophen). Three patients were sedated with midazolam. Six patients were treated with Omiderm and/or Suprathel; 5 patients were discharged within 1 week. One patient (No. 4) died after severe Pseudomonas aeruginosa sepsis, another patient (No. 1) needed special care for his prematurity after recovering from SSSS. 
Table 1a. Summary of patient data

\begin{tabular}{|c|c|c|c|c|c|c|c|}
\hline & \multicolumn{7}{|l|}{ Patient } \\
\hline & 1 & 2 & 3 & $4^{*}$ & 5 & 6 & 7 \\
\hline Age & 3 days & 7 months & 6 days & 18 days & 6 days & 5 months & 11 months \\
\hline Gender & male & male & male & male & male & female & male \\
\hline Total affected area, \% & 70 & 20 & 70 & 70 & 90 & 30 & 40 \\
\hline Source of infection & umbilical & airway & umbilical & umbilical & umbilical & nose & no source \\
\hline Histopathology: roof of blister & + & + & + & + & - & - & - \\
\hline Skin therapy: Omiderm ${ }^{\circledR}$ & + & + & $+^{\dagger}$ & - & + & + & + \\
\hline \multicolumn{8}{|l|}{ Highest dose of } \\
\hline morphine, $\mu \mathrm{g} / \mathrm{kg} / \mathrm{h}$ & 15 & 20 & 20 & 20 & 40 & 10 & 20 \\
\hline Intensive care, days & 3 & 3 & 4 & 4 & 6 & 4 & 3 \\
\hline
\end{tabular}

Seven cases with SSSS. ${ }^{*}$ Deceased. ${ }^{\dagger}$ Also treated with Suprathel ${ }^{\circledR}$. Case 5 published before [11].

Table 1b. Summary of diagnosis and treatment

\begin{tabular}{|c|c|}
\hline Diagnosis & \\
\hline Clinical picture & Age younger than 5 years \\
\hline & Source of infection: umbilical, conjunctivitis, perioral infection \\
\hline & Erythema with blistering \\
\hline & Progression within hours/day \\
\hline Histopathology & Roof of blister \\
\hline Culture & Skin, umbilical and nose (S. aureus) \\
\hline Treatment & \\
\hline Environment & Sterile undersheets (non-sticky) \\
\hline & Control of humidity and temperature \\
\hline & Isolate patient, control contamination of other patients \\
\hline Antibiotics & Neonates: sepsis therapy with aminoglycosides (Staphylococcus, Pseudomonas) \\
\hline & Flucloxacillin \\
\hline Control fluid balance & Maintenance fluid \\
\hline & Extra fluid based on formula $(35+\%$ damage skin $) \times$ BSA $\left(\mathrm{m}^{2}\right)=\mathrm{ml} / \mathrm{h}$ \\
\hline Analgesia and sedation & Covering skin \\
\hline Alrargessa ardo sedation & $\begin{array}{l}\text { Acetammopnen } \\
\text { Opiates }\end{array}$ \\
\hline & Midazolam \\
\hline Skin care & Covering with skin substitutes (Omiderm, Suprathel) \\
\hline & Minimal handling \\
\hline & No application of antibiotic ointments \\
\hline
\end{tabular}

Diagnosis

Clinical picture

Histopathology

Culture

\section{Treatment}

Environment

\section{Antibiotics}

Control fluid balance

Analgesia and sedation

Skin care
Age younger than 5 years

Erythema with blistering

Roof of blister

Sterile undersheets (non-sticky)

Control of humidity and temperature

Flucloxacillin

Extra fluid based on formula $(35+\%$ damage skin $) \times$ BSA $\left(\mathrm{m}^{2}\right)=\mathrm{ml} / \mathrm{h}$

\section{Opiates}

Minimal handling

No application of antibiotic ointments

\section{Discussion}

SSSS is a potential life-threatening disease especially in the first month of life. Differential diagnosis can be difficult in the prodromal phase with erythroderma [12]. When blistering is the presenting symptom, SSSS should be differentiated from bullous impetigo, epidermolysis bullosa, mastocytosis, pemphigus and other congenital bullous disorders such as bullous ichthyosis and toxic epidermal necrolysis (TEN). TEN is extremely rare in in- fancy and caused by necrosis of the epidermis, whereas SSSS is caused by acantholysis [13-15]. In TEN the oral mucosa is always involved, whereas it is spared in SSSS. A skin biopsy for histological examination is not necessary, the roof of the blisters shows acantholytic cells in SSSS. The Tzanck smear is also an easy method to illustrate acantholysis [16]. Determining the exfoliative toxin produced by the $S$. aureus can be helpful in epidemiological studies during outbreaks on neonatal wards but is not necessary for the diagnosis SSSS [17]. To prevent out- 
breaks of SSSS on neonatal wards it is necessary to isolate the patient and during outbreaks it is also necessary to treat healthcare workers or parents with mupirocin to eradicate nasal carriage of $S$. aureus and prevent contamination of other patients [17].

Recently, Blyth et al. [3] described the diagnosis and treatment in 4 older children with SSSS. Skin treatment consists of silver sulfadiazine creams and daily dressings change under anesthesia on the unit with sedation. Antibiotic or antiseptic ointments should also not be applied on large areas of the skin because of systemic toxicity by absorption of antibiotics, especially in neonates or infants $[5,7]$. Therefore, treatment is required with skin substitutes that are applied only. We introduced a new skin treatment for SSSS with Omiderm in a case report in 2006 [11]. After that period, we treated 6 patients with SSSS and used Omiderm, in 1 case added with Suprathel (case 3). Others reported the use of Omiderm protecting the skin of low birth weight infants or in aplasia cutis congenita $[18,19]$.

A case report emphasizes the use of Suprathel in the treatment of an infant with TEN [20]. Recently, Mueller et al. [21] reported an infant with SSSS who was successfully treated with Suprathel. Greenwood et al. [22] described the use of Mepitel ${ }^{\circledR}$ in SSSS patients. The major disadvantages of the use of Mepitel are that it is not transparent which renders it impossible to evaluate the skin and daily changing of the covering bandages are required.

Omiderm and Suprathel must be left on the skin because both skin substitutes are synthetic and there is no need to change the dressing (fig. 1c). The dressings will gradually peel off on their own (fig. 1d). Suprathel is also biodegradable (see Appendix). In older children we also prefer treatment with skin substitutes to improve pain relief and fluid control.

The proposed treatment requires hospitalization, as intravenous antibiotics are generally necessary to eradicate the source of staphylococcal infection or colonization. However, antibiotics do not influence the progression of the 'skin' manifestations of SSSS. Affected skin and blisters were in most cases sterile in classical SSSS by definition, but exceptions are reported [23]. The toxins will be neutralized by antibodies and are eliminated in the urine $[1,8]$. Generally, sepsis therapy will be chosen for neonates, which also covers infections with $P$. aeruginosa. Case 4 was not treated with skin substitutes and deceased, unfortunately due to $P$. aeruginosa sepsis. This case stresses the indication of early use of broad-spectrum antibiotics to prevent $P$. aeruginosa sepsis.
After determining the S. aureus, a penicillinase-resistant, anti-staphylococcal antibiotic such as flucloxacillin is preferred. Depending on the response to treatment, oral antibiotics can be substituted within several days. The use of pooled human immunoglobulin or fresh-frozen plasma in SSSS has been reported [3], but has not been investigated in randomized controlled trials [24]. The use of corticosteroids is contraindicated [4]. In general, patients with SSSS have extreme pain as did our patients. Not only touch but even a draught can cause pain. Neonates may become irritated but may also present with hypotonia and lethargic states due to extreme pain. Therefore, it is important to cover the wounds with an adhesive skin substitute.

We acknowledge the limitation of our study as no control group was used. Our first experience with Omiderm was positive and has shown that the use of Omiderm and Suprathel has an analgesic effect. These dressings should be applied as soon as possible on the exfoliated skin. In addition, pain relief is necessary. Paracetamol in combination with opiates is required. In our patients we administered paracetamol and intravenous morphine (1 case needed dosages up to $40 \mu \mathrm{g} / \mathrm{kg} / \mathrm{h}$ ) and in 3 cases we also added low-dose midazolam $(0.1 \mathrm{mg} / \mathrm{kg} / \mathrm{h})$. NSAIDs are contraindicated. Premature neonates with diminished renal function due to hypovolemia, immaturity or use of NSAIDs are prone to SSSS due to limited renal elimination clearance of exfoliative toxins $[1,8]$.

In most cases, we initially started with a fluid bolus when the circulation is threatened by hypovolemia. Many referring specialists calculate the fluid needed on the basis of burns resuscitation formulas (Parkland formula). However, patients with SSSS are not similar to burn patients who have extensive dermal necrosis and capillary leakage. The amount of fluid administered using the Parkland formula is too much and there is a risk of fluid overload and hyponatremia [3]. In our patients, we used another formula that is used in burn care, after the initial resuscitation phase [25]. For children, we advise the maintenance requirements plus (35 + TBSA (\%)) $\times(\mathrm{BSA} /$ $\mathrm{m}^{2}$ ) = the amount of fluid in milliliters per hour. There is a risk of hyponatremia and isotonic fluids such as saline $(0.9 \% \mathrm{NaCl})$ should be used when substituting for fluid losses. In some cases the serum albumin or colloid osmotic pressure is low and human albumin or plasma expanders are necessary. To control body temperature, neonates are nursed in an incubator with high humidity. Children are sometimes nursed in burn units where air, humidity and ambient temperature are controlled. Enteral feeding is encouraged and should be started as soon 
as possible. Our therapeutic approach is summarized in table $1 \mathrm{~b}$.

In conclusion, although the external signs of SSSS appear worse, infants generally recover well and healing is usually complete within 5-7 days after starting treatment. Skin substitutes and special care including appropriate fluids and analgesics are essential to achieve the best results.

\section{Acknowledgement}

The authors would like to thank Prof. D. Tibboel of the Paediatric Intensive Care Unit at the Erasmus MC-Sophia's Children's Hospital of Rotterdam for critically reading the manuscript.
Appendix. Characteristics of Omiderm ${ }^{\circledR}$ versus Suprathel ${ }^{\circledR}$

\begin{tabular}{lll}
\hline Brand name & Omiderm & Suprathel \\
\hline Generic name & $\begin{array}{l}\text { water-vapour } \\
\text { permeable poly- }\end{array}$ & $\begin{array}{l}\text { synthetic copolymer } \\
\text { based on dl-lactic }\end{array}$ \\
& urethane film & acid \\
Application time & once & once \\
Non-toxic & + & + \\
Flexibility & + & + \\
Elasticity & \pm & + \\
Sticky & - & + \\
Pain relief & + & + \\
Transparent & + & after attachment \\
Expensive & - & + \\
\hline
\end{tabular}

\section{References}

1 Ladhani S: Understanding the mechanism of action of the exfoliative toxins of Staphylococcus aureus. FEMS Immunol Med Microbiol 2003;39:181-189.

-2 Stanley JR, Amagai M: Pemphigus, bullous impetigo, and the staphylococcal scaldedskin syndrome. N Engl J Med 2006;355: 1800-1810.

3 Blyth M, Estela C, Young AE: Severe staphylococcal scalded skin syndrome in children. Burns 2008;34:98-103.

-4 Patel GK, Finlay AY: Staphylococcal scalded skin syndrome: diagnosis and management. Am J Clin Dermatol 2003;4:165-175.

5 Patel GK: Treatment of staphylococcal scalded skin syndrome. Exp Rev Anti Infect Ther 2004;2:575-587.

6 Gait RC, Johnston GA: Acute skin conditions in children. Br J Hosp Med 2008;69:4.

7 Johnston GA: Treatment of bullous impetigo and the staphylococcal scalded skin syndrome in Infants. Expert Rev Anti Infect Ther 2004;2:439-446.

$\checkmark 8$ Ladhani S, Joannou CL, Lochrie DP, Evans RW, Poston SM: Clinical, microbial, and biochemical aspects of the exfoliative toxins causing staphylococcal scalded-skin syndrome. Clin Microbiol Rev 1999;12:224242.

\9 Uhlig C, Rapp M, Hartmann B, Hierlemann H, Planck H, Dittel KK: Suprathel ${ }^{\circledR}$ - an innovative, resorbable skin substitute for the treatment of burn victims. Burns 2007;33: 221-229.
10 Benmier P: Omiderm ${ }^{\circledR}$ as an initial burn dressing. J Burn Care Rehabil 1994;15:461.

11 Baartmans MG, Maas MH, Dokter J: Neonate with staphylococcal scalded skin syndrome. Arch Dis Child Fetal Neonatal Ed 2006;91:F25.

12 Hoeger PH, Harper JI: Neonatal erythroderma: differential diagnosis and management of the 'red baby'. Arch Dis Child 1998;79: 186-191.

13 De Groot R, Oranje AP, Vuzevski VD: Staph ylococcal scalded skin syndrome. Ned Tijdschr Geneeskd 1984;128:1459-1463.

14 Scully MC, Frieden IJ: Toxic epidermal necrolysis in early infancy. J Am Acad Dermatol 1992;27:340-344.

15 Amagai M: Pemphigus as a paradigm of autoimmunity and cell adhesion. Keio J Med 2002;51:133-139.

16 Oranje AP, Folkers E: The Tzanck smear: old, but still of inestimable value. Pediatr Dermatol 1988;5:127-129.

17 Jursa-Kulesza J, Kordek A, Kopron K, Wojciuk B, Giedrys-Kalemba S: Molecular studies of an impetigo bullosa epidemic in fullterm infants. Neonatology 2009;96:61-68.

$\rightarrow 18$ Barak M, Hershkowitz S, Rod R, Dror S: The use of a synthetic skin covering as a protective layer in the daily care of low birth weight infants. Eur J Pediatr 1989;148:665-666.
19 Canter HI, Vargel I, Nasir S, Kayikcioglu A: Use of water-vapour permeable polyurethane film $\left(\right.$ Omiderm $\left.^{\circledR}\right)$ in the non-surgical treatment of aplasia cutis congenital. Scand J Plast Reconstr Surg Hand Surg 2004;38:232235.

20 Pfurtscheller K, Zobel G, Roedl S, Trop M: Use of Suprathel ${ }^{\circledR}$ dressings in a young infant with TEN. Pediatr Dermatol 2008;25:541543.

21 Mueller E, Haim M, Petnehazy T, AchamRoschitz B, Trop M: An innovative local treatment for staphylococcal scalded skin syndrome. Eur J Clin Microbiol Infect Dis 2010;29:893-897.

-22 Greenwood JE, Dunn KW, Davenport PJ: Experience with severe extensive blistering skin disease in a paediatric burns unit. Burns 2000;26:82-87.

23 Makhoul IR, Imad K, Hashman N, Sujov P: Staphylococcal scalded-skin syndrome in a very low birth weight premature infant. Pediatrics 2001;108:E16.

24 Orange JS, Hossny EM, Weiler CR, et al: Use of intravenous immunoglobulin in human disease: a review of evidence by members of the Primary Immunodeficiency Committee of the American Academy of Allergy, Asthma and Immunology. J Allergy Clin Immunol 2006;117(suppl):S525-S553.

25 Warden GD, Chapter 9, Fluid resuscitation and early management: On: David N Herndon. Total Burn Care. 3e edition Saunders Elsevier 2006, pp 14-32. 